\title{
Original Article (short paper) \\ A cross-cultural study of physical activity and sedentariness in youth from Mozambique and Portugal
}

\author{
Fernanda Karina dos Santos ${ }^{1}$; António Prista ${ }^{2}$; Thayse Natacha Gomes ${ }^{3}$; Michele Souza ${ }^{4}$; Francisco Tchonga ${ }^{2}$; \\ Albertino Damasceno ${ }^{5}$; Peter T. Katzmarzyk ${ }^{6}$; José Maia $^{3}$ \\ ${ }^{1}$ Universidade Federal de Viçosa, UFV, Viçosa, MG, Brasil; ${ }^{2}$ Universidade Pedagógica, UP, Maputo, \\ Moçambique; ${ }^{3}$ Universidade do Porto, Porto, Portugal; ${ }^{4}$ Universidade Federal de Santa Catarina, \\ UFSC, Florianópolis, SC, Brasil; ${ }^{5}$ Universidade Eduardo Mondlane, UEM, Maputo, Moçambique; \\ ${ }^{6}$ Pennington Biomedical Research Center, Louisiana State University, Baton Rouge, LA, USA
}

\begin{abstract}
Aim: The purpose of this study was to analyse the effects of age, sex, body mass index (BMI) and country of origin (Mozambique versus Portugal) on physical activity and sedentariness. Methods: Sample size was comprised of 593 adolescents from Mozambique $(n=258)$ and Portugal $(n=335)$, aged 10-15 years old. Height and weight were measured, and BMI was computed; furthermore, subjects were classified in two groups (normal weight and overweight/obese). The mean time (min/day) spent in moderate-to-vigorous physical activity (MVPA), light physical activity (LPA), and sedentary activity were assessed using the GT3X Actigraph accelerometer over at least 4 days ( 1 weekend day) with a minimum of 10 hours/day of monitoring. Multiple regression analysis was done in SPSS 20. Results: A low percentage of Mozambican (3.9\%) and Portuguese (4.3\%) youth complied with the MVPA recommendations $\left(60 \mathrm{~min} \cdot \mathrm{day}^{-1}\right)$. However, Portuguese boys spend more time in MVPA. Girls and those with higher BMI spend more time in sedentary activities and less time in MVPA and LPA; older adolescents spend more time in sedentary activities and less time in LPA. There is a significant effect of the country of origin on MVPA, favouring Portuguese youth. Conclusions: Results suggest country differences in MVPA between Mozambican and Portuguese youth - the Mozambicans are less involved in MVPA than the Portuguese, probably reinforcing the undesirable effect of the urbanization process in developing nations.
\end{abstract}

Keywords: physical activity; sedentariness; youth; cross-cultural

\section{Introduction}

The health benefits of moderate-to-vigorous physical activity (MVPA), especially among youth, are well known ${ }^{1,2}$. It is also acknowledged that, around the world, the urbanization process affects children and adolescents' daily lives in many different ways $^{3-5}$. Further, this impact is more evident in developing countries, causing drastic changes in lifestyles ${ }^{6}$, leading to decreasing levels in habitual physical activity (PA), increasing levels in sedentariness ${ }^{6}$, and as a consequence, an escalation in the prevalence of overweight and obesity ${ }^{7,8}$.

Despite both developed and developing countries being affected by the urbanization process, they are in different stages of this process ${ }^{9}$. Developed nations are in the so-called "last stage" of nutritional transition", with a high prevalence of sedentariness and obesity, but with people becoming more aware of the benefits of balanced diets and physically active lifestyles, and that changing diets and PA habits will, in all likelihood, prevent or delay co-morbidities related to physical inactivity and obesity. Developing nations, such as Sub-Saharan countries are, in general, in the fourth stage of this transition?, characterized by people becoming more affluent with the adoption of a westernized way of life, with the expected increments of overweight/obesity prevalence and a more sedentary daily life. As a consequence, there is a trend in developing nations for high prevalence of sedentariness and a relevant decrease in MVPA levels, namely among youth, with similar frequencies of those found in developed nations ${ }^{10,11}$.

PA differences in European countries have been systematically studied. For example, Aibar, Bois, Generelo, Zaragoza Casterad, Paillard ${ }^{12}$ reported that Spanish adolescents were more physically active than French adolescents; in addition they reported that only $35.9 \%$ of adolescents complied with current PA guidelines (60 $\mathrm{min}$ /day of MVPA). Further, Ramirez-Rico, Hilland, Foweather, Fernandez-Garcia, Fairclough ${ }^{13}$ reported that English adolescents were less sedentary and more active than their Spanish peers, and the percentage of adolescents achieving the recommended MVPA levels was about $25 \%$ overall.

To our knowledge, few studies have investigated differences in PA among children from countries with diverse socio-economic characteristics. In a recent review of worldwide variation in PA levels of adolescents from 105 countries, Hallal et al. ${ }^{10}$ reported that more than $80 \%$ of youth do not achieve the recommended daily MVPA levels; further, this prevalence tended to be lower 
in developing nations. In the African context, Peltzer ${ }^{14}$ reported that only $14.2 \%$ of children from 8 countries were physically active ( 5 days or more in a week with at least $60 \mathrm{~min} \cdot$ day $^{-1}$ ); additionally there are large differences among countries meeting the PA guidelines, $17.7 \%$ in Uganda and $9.0 \%$ in Zambia.

Portugal and Mozambique are countries with different social, economic and cultural characteristics. A previous study conducted in 2009 comparing PA levels in 6- to 16-year-old school-age children and adolescents from these two countries ${ }^{15}$ reported that rural Mozambican youth engaged in significantly higher PA levels than their Portuguese peers. However, due the urbanization process that has affected the lifestyles of youth from these two countries, this scenario could not be seen in a more recent study ${ }^{16,17}$. Recent data have shown that the proportion of Portuguese children aged 10-11 years complying with the recommendation of at least $60 \mathrm{~min} \cdot$ day $^{-1}$ of MVPA is 36\% (51.6\% for boys, $22.5 \%$ for girls), and that this prevalence decreases with age, with only $4 \%$ ( $7.9 \%$ of boys, $1.2 \%$ of girls) of adolescents aged 16-17 years attaining the recommended MVPA guidelines ${ }^{17}$. Although there is no nationally representative data for PA in Mozambican youth, there is some evidence of a decline during the last decades ${ }^{15,16}$. Given that the urbanization process may be contributing to a decrease in children and adolescent's PA levels, the purpose of this study was to analyse the effects of age, sex, BMI and country of origin (Mozambique versus Portugal) on levels of PA and sedentariness in youth. Hence, we hypothesize the presence of significant associations of these covariates in youth PA levels and sedentariness in both countries.

\section{Methods}

\section{Sample}

Children and adolescents, aged 10-15 years, from Mozambique (Maputo) and Portugal (Porto metropolitan area), comprise the sample of the present study. The Mozambican sample is part of the Human Biological Variability-Implications for Physical Education, Sports, Preventive Medicine and Public Health research project, aiming to describe patterns of human variability in growth, biological maturation and development of Mozambican youth ${ }^{18}$. The Portuguese sample comes from The Oporto Growth, Health and Performance Study, aiming to investigate the relationship among physical growth, body composition, PA, physical fitness, nutritional and health behaviours in Portuguese youth ${ }^{19}$.

Data collection took place during the 2012 and 2013 school years in Mozambique, and in 2011, 2012 and 2013 in Portugal. Children and adolescents were randomly selected from basic and secondary schools in each country, and a total of 593 subjects were included in the analysis: 258 Mozambicans (108 boys, 150 girls), and 335 Portuguese (141 boys, 194 girls). Children with chronic diseases, physical handicaps, or psychological disorders that might impair their daily routines, physical activities or motor testing, and those younger than 10 or older than 15 years, were excluded during sample selection and/or data screening. All children involved in the study had a written consent signed by parents or legal guardians. The Mozambican National Bioethics Committee (Mozambique, ethical number: 44/CNBS/05) and University of Porto ethics committee (Portugal, ethical number: 15/CEUP/2012), as well as school authorities, approved each study protocol.

\section{Maputo City and Porto Metropolitan areas and socio- demographic characteristics}

Maputo and Porto are two different cities from two different countries in cultural, social and economic terms. Briefly, the city of Maputo (the capital) has 1,194,121 inhabitants with a life expectancy of 57.5 years; its population density is of $3,443.6$ per $\mathrm{km}^{2}$, and the population growth rate is $1.37 \%$. The illiteracy rate and the child mortality are $9.8 \%{ }^{20}$ and $55.8 / 1000$ births $^{21}$, respectively. In comparison, the Porto metropolitan area has $1,287,256$ inhabitants, with a population density of $1,580.3$ per $\mathrm{km}^{22,23}$ and a population growth rate of $-0.58 \%$. The life expectancy of 78 years, the child mortality of 3.1/1000 births, and the illiteracy rate of $3.3 \%$ makes it as one of the most developed in Portugal ${ }^{22}$.

\section{Anthropometry}

Standardized procedures described by Lohman, Roche, Martorel $1{ }^{24}$ were used in data collection in the two countries. In Portugal, children were measured wearing light clothes, without shoes or socks, whereas in Mozambique children were assessed without shoes and naked in two private rooms, one for each sex (girls were measured by female technicians, and boys were measured by male technicians). Height was measured to the nearest $0.1 \mathrm{~cm}$ with the head positioned in the Frankfurt plane with a portable stadiometer (Holtain Ltd, UK); a calibrated portable Seca (Seca, Germany) scale (in Mozambique) and a portable bioelectrical impedance (TANITA BC-418 MA Segmental Body Composition Analyser; Tanita, Corporation, Tokyo, Japan) scale (in Portugal) were used to measure weight.

BMI was computed using the standard formula [weight $(\mathrm{kg}) /$ height $\left.(\mathrm{m})^{2}\right]$, and the International Obesity Task Force cut points ${ }^{25}$ were used to classify subjects in two groups (normal weight and overweight/obese)

\section{Physical Activity and Sedentary Time}

PA and sedentary time (ST) were monitored by Actigraph GT3X accelerometers (ActiGraph, Pensacola, FL). Children and adolescents wore the accelerometer at their waist on an elasticized belt, placed on the right mid-axillary line, for at least 7 days, including 2 weekend days; all were asked to remove the accelerometers only when sleeping and when performing waterbased activities (such as taking a shower or swimming). To be eligible for this study, youth had at least 4 days (including at least one weekend day) with a minimum of 10 hours of monitoring 
per day. All 593 children fulfilled this condition. Non-wear time was defined as any sequence of at least 20 consecutive minutes of zero activity counts ${ }^{26}$.

Using cut-points developed by Treuth et al. ${ }^{27}$ and 1-minute epochs, the following PA phenotypes were calculated: mean $\operatorname{MVPA}\left(\geq 3000\right.$ counts $\left.\cdot \mathrm{m}^{-1}\right)$, light PA (LPA; $100-2999$ counts $\left.\cdot \mathrm{m}^{-1}\right)$ and $\mathrm{ST}\left(<100\right.$ counts $\left.\cdot \mathrm{m}^{-1}\right)$.

\section{Statistical Analysis}

Initially, basic descriptive statistics and t-test, by sex and country, were computed. Analysis of covariance, adjusted for age and mean wear time of the accelerometer (WTA), was used to compare mean differences in BMI, MVPA, LPA and ST among Portuguese and Mozambican boys and girls. Further, multiple regression was used to investigate the effect of country (Portugal vs Mozambique), sex, age and BMI on MVPA, LPA and ST. All statistical analysis was done on SPSS 20 and the significance level was set at 5\%.

\section{Results}

Descriptive statistics for BMI, PA and ST are shown in Table 1. On average, Portuguese and Mozambican boys and girls failed to achieve the $60 \mathrm{~min} \cdot \mathrm{day}^{-1}$ recommended MVPA levels. Except for MVPA, significant differences were found for LPA and ST - Mozambican children and adolescents have, on average, more LPA and ST; further, Portuguese youth have higher BMI values.

Table 1: Descriptive statistics (mean $\pm \mathrm{SD}), \mathrm{t}$ and $\mathrm{p}$-values by sex and country.

\begin{tabular}{|c|c|c|c|c|c|}
\hline & & $\begin{array}{c}\text { Portugal } \\
\text { Mean } \pm \text { SD }\end{array}$ & $\begin{array}{c}\text { Mozambique } \\
\operatorname{Mean} \pm \text { SD }\end{array}$ & $\mathbf{t}$ & p-value \\
\hline \multirow{5}{*}{ Boys } & $\mathrm{N}$ & 141 & 108 & & \\
\hline & BMI $\left(\mathrm{kg} \cdot \mathrm{m}^{-2}\right)$ & $20.3 \pm 3.5$ & $18.8 \pm 3.6$ & 3.466 & 0.001 \\
\hline & $\operatorname{MVPA}\left(\min \cdot \mathrm{d}^{-1}\right)$ & $31.0 \pm 21.5$ & $27.6 \pm 18.3$ & 1.284 & 0.200 \\
\hline & $\operatorname{LPA}\left(\min \cdot d^{-1}\right)$ & $378.0 \pm 81.7$ & $421.3 \pm 108.5$ & -3.590 & $<0.001$ \\
\hline & $\mathrm{ST}\left(\min \cdot \mathrm{d}^{-1}\right)$ & $417.0 \pm 86.2$ & $492.9 \pm 118.9$ & -5.609 & $<0.001$ \\
\hline \multirow{5}{*}{ Girls } & $\mathrm{N}$ & 194 & 150 & & \\
\hline & BMI $\left(\mathrm{kg} \cdot \mathrm{m}^{-2}\right)$ & $20.9 \pm 3.6$ & $20.1 \pm 3.7$ & 2.084 & 0.040 \\
\hline & $\operatorname{MVPA}\left(\min \cdot \mathrm{d}^{-1}\right)$ & $17.0 \pm 13.4$ & $16.46 \pm 13.79$ & 0.340 & 0.734 \\
\hline & $\operatorname{LPA}\left(\min \cdot \mathrm{d}^{-1}\right)$ & $354.8 \pm 86.9$ & $388.19 \pm 100.97$ & -3.230 & 0.001 \\
\hline & $\mathrm{ST}\left(\min \cdot \mathrm{d}^{-1}\right)$ & $457.1 \pm 87.5$ & $513.81 \pm 114.81$ & -5.022 & $<0.001$ \\
\hline \multirow{5}{*}{ Total } & $\mathrm{N}$ & 335 & 258 & & \\
\hline & BMI $\left(\mathrm{kg} \cdot \mathrm{m}^{-2}\right)$ & $20.7 \pm 3.6$ & $19.5 \pm 3.7$ & 3.786 & $<0.001$ \\
\hline & $\operatorname{MVPA}\left(\min \cdot \mathrm{d}^{-1}\right)$ & $22.9 \pm 18.6$ & $21.1 \pm 16.8$ & 1.161 & 0.246 \\
\hline & $\operatorname{LPA}\left(\min \cdot \mathrm{d}^{-1}\right)$ & $364.6 \pm 85.4$ & $402.1 \pm 105.2$ & -4.658 & $<0.001$ \\
\hline & $\mathrm{ST}\left(\min \cdot \mathrm{d}^{-1}\right)$ & $440.2 \pm 89.1$ & $505.1 \pm 116.8$ & -7.413 & $<0.001$ \\
\hline
\end{tabular}

BMI: Body mass index; MVPA: moderate-to-vigorous physical activity; LPA: Light physical activity; ST: Sedentary time.

Figure 1 presents graphical representation of the mean values of BMI, PA and ST, adjusted for age and WTA (except for BMI that was only adjusted for age). After adjustments, BMI differences remained, but no statistically significant differences were observed for LPA and ST between countries; on the other hand, MVPA differences became significant for boys and for the total sample.

A very low frequency of children and adolescents, from both countries, complied with the recommended MVPA daily levels only $4.3 \%$ in Mozambique and 3.9\% in Portugal. Additionally, a moderate to high frequency of children were classified as being overweight/obese: $18.2 \%$ in Mozambique and $32.5 \%$ in Portugal.
Multiple regression analysis results are presented on Table 3. Mozambican children $(\beta=-5.743, p=0.001)$, girls $(\beta=11.700$, $p<0.001)$ and those with high BMI $(\beta=-0.989, p<0.001)$ spend, on average, less time in MVPA. Similarly, girls $(\beta=17.027, p=0.009$ for LPA; $\beta=-28.725, p<0.001$ for ST), older youth $(\beta=-27.083$, $p<0.001$ for LPA; $\beta=26.927, p<0.001$ for ST), and those with higher BMI $(\beta=-2.989, p=0.001$ for LPA; $\beta=3.978, p<0.001$ for ST) spend less time in LPA, but have more ST; country of origin did not have a significant effect on LPA or ST. WTA was positively correlated with the three phenotypes, meaning that children who used the accelerometer for more time tend to report more time spent in PA and sedentariness. 
Figure 1: Graphical representation of means \pm standard errors for BMI, PA and ST after adjustment for age and WTA, by country.

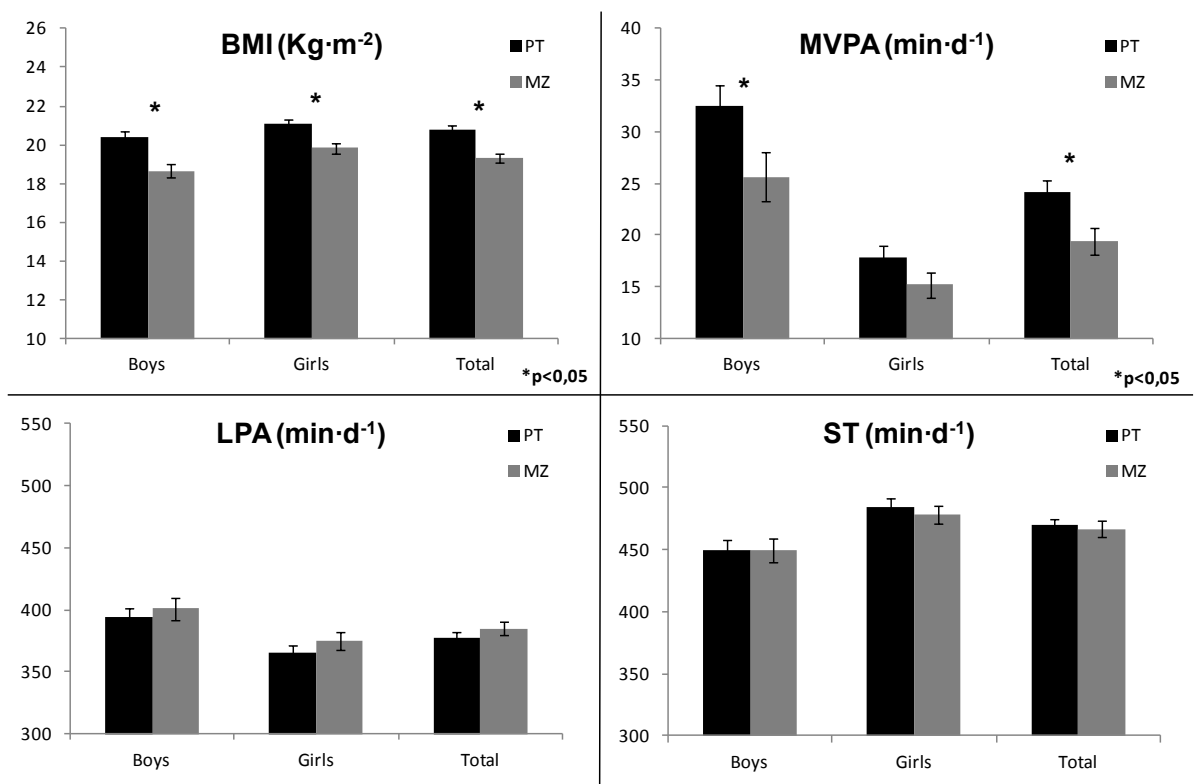

BMI: Body mass index; MVPA: moderate-to-vigorous physical activity; LPA: Light physical activity; ST: Sedentary time; PT: Portugal; MZ: Mozambique.

Table 2: Frequency of children attaining recommended MVPA levels, by age, sex, and country.

\begin{tabular}{|c|c|c|c|c|c|}
\hline \multirow{2}{*}{ Year } & \multirow{2}{*}{ PA Groups } & \multicolumn{2}{|c|}{ Boys } & \multicolumn{2}{|c|}{ Girls } \\
\hline & & Portugal & Mozambique & Portugal & Mozambique \\
\hline \multirow{2}{*}{10} & $>60 \mathrm{~min} \cdot \mathrm{d}^{-1}$ & $2(10.0 \%)$ & $2(16.7 \%)$ & --- & --- \\
\hline & $<60 \mathrm{~min} \cdot \mathrm{d}^{-1}$ & $18(90.0 \%)$ & $10(83.3 \%)$ & $23(100 \%)$ & $17(100 \%)$ \\
\hline \multirow{2}{*}{11} & $>60 \mathrm{~min} \cdot \mathrm{d}^{-1}$ & --- & $2(14.3 \%)$ & $1(1.7 \%)$ & --- \\
\hline & $<60$ min $\cdot \mathrm{d}^{-1}$ & $44(100 \%)$ & $12(85.7 \%)$ & $57(98.3 \%)$ & $17(100 \%)$ \\
\hline \multirow{2}{*}{12} & $>60 \mathrm{~min} \cdot \mathrm{d}^{-1}$ & $3(11.1 \%)$ & $1(4.8 \%)$ & $1(2.7 \%)$ & $1(4.2 \%)$ \\
\hline & $<60 \mathrm{~min} \cdot \mathrm{d}^{-1}$ & $24(88.9 \%)$ & $20(95.2 \%)$ & $36(97.3 \%)$ & $23(95.8 \%)$ \\
\hline \multirow{2}{*}{13} & $>60 \mathrm{~min} \cdot \mathrm{d}^{-1}$ & $4(19.0 \%)$ & $2(8.7 \%)$ & $1(3.3 \%)$ & --- \\
\hline & $<60$ min $\cdot \mathrm{d}^{-1}$ & $17(81 \%)$ & $21(91.3 \%)$ & $29(96.7 \%)$ & $26(100 \%)$ \\
\hline \multirow{2}{*}{14} & $>60 \mathrm{~min} \cdot \mathrm{d}^{-1}$ & --- & $2(8.7 \%)$ & --- & $1(2.2 \%)$ \\
\hline & $<60 \mathrm{~min} \cdot \mathrm{d}^{-1}$ & $20(100 \%)$ & $21(91.3 \%)$ & $32(100 \%)$ & $45(97.8 \%)$ \\
\hline \multirow{2}{*}{15} & $>60 \mathrm{~min} \cdot \mathrm{d}^{-1}$ & $1(11.1 \%)$ & --- & --- & --- \\
\hline & $<60 \mathrm{~min} \cdot \mathrm{d}^{-1}$ & $8(88.9 \%)$ & $15(100 \%)$ & $14(100 \%)$ & $20(100 \%)$ \\
\hline \multirow{2}{*}{ Total } & $>60 \mathrm{~min} \cdot \mathrm{d}^{-1}$ & $10(7.1 \%)$ & $9(8.3 \%)$ & $3(1.5 \%)$ & $2(1.3 \%)$ \\
\hline & $<60 \mathrm{~min} \cdot \mathrm{d}^{-1}$ & $131(92.9 \%)$ & 99 (91.7\%) & $191(98.5 \%)$ & $148(98.7 \%)$ \\
\hline
\end{tabular}

PA: physical activity; MVPA: moderate-to-vigorous physical activity.

Table 3: Multiple regression analysis results for MVPA, LPA and ST predictors.

\begin{tabular}{llll}
\hline & \multicolumn{1}{c}{ MVPA $\left(\mathbf{m i n}^{\left.-d^{-1}\right)}\right.$} & \multicolumn{1}{c}{ LPA (min.d $\left.{ }^{-1}\right)$} & \multicolumn{1}{c}{ ST $\left(\mathbf{m i n}^{-1} \mathbf{d}^{-1}\right)$} \\
\hline Model & $\mathrm{R}^{2}=0.18, \mathrm{SEE}=16.23$ & $\mathrm{R}^{2}=0.36, \mathrm{SEE}=77.56$ & $\mathrm{R}^{2}=0.64, \mathrm{SEE}=82.33$ \\
Sex $^{1}$ & $\beta=11.70, p<0.001$ & $\beta=17.03, p=0.009$ & $\beta=-28.73, p<0.001$ \\
Age $($ years $)$ & $\beta=0.16, p=0.727$ & $\beta=-27.08, p<0.001$ & $\beta=26.93, p<0.001$ \\
BMI $\left(\mathrm{kg} \cdot \mathrm{m}^{-2}\right)$ & $\beta=-0.99, p<0.001$ & $\beta=-2.99, p=0.001$ & $\beta=3.98, p<0.001$ \\
WTA $\left(\mathrm{min}^{-1} \mathrm{~d}^{-1}\right)$ & $\beta=0.03, p=0.005$ & $\beta=0.49, p<0.001$ & $\beta=4.09, p<0.001$ \\
Country $^{2}$ & $\beta=-5.74, p=0.001$ & $\beta=3.67, p=0.654$ & $\beta=2.08, p=0.812$ \\
\hline
\end{tabular}

MVPA: moderate-to-vigorous physical activity; LPA: Light physical activity; ST: Sedentary time; BMI: Body mass index; WTA: wear time of the accelerometer. ${ }^{1}$ Sex: girls $=0$; boys $=1 ;{ }^{2}$ Country: Portugal $=0$; Mozambique $=1$ 


\section{Discussion}

In this paper we found differences in LPA and ST between countries, where Mozambican youth (especially boys) spent more time in these behaviours when compared with their Portuguese peers. Differences in PA between children and adolescents from many nationalities have been reported by Aibar, Bois, Generelo, Zaragoza Casterad, Paillard ${ }^{12}$, Ramirez-Rico, Hilland, Foweather, Fernandez-Garcia, Fairclough ${ }^{13}$, and Verloigne et al. ${ }^{28}$, showing differences not only in distinct PA expressions, but also in sedentariness (both determined by accelerometer). Similarly, using questionnaire data from 8 African countries, Peltzer ${ }^{14}$ reported differences in school-children and adolescents' PA. These results highlight the potential of social, cultural and environmental correlates on youth behaviour, namely their $\mathrm{PA}^{29,30}$.

Cross-cultural studies contrasting youth PA differences from countries with diverse socio-economic characteristics are scarce. Additionally, if available they frequently report PA levels or sedentariness by country or region, aiming to explore the worldwide patterns in these behaviours ${ }^{10,31}$. A previous study ${ }^{15}$ compared PA levels (assessed by accelerometry) between rural Mozambican and urban Portuguese youth, and reported that Mozambicans had significantly higher total PA, showed less PA decline with age, but engaged in fewer minutes at high intensity PA than their Portuguese peers. The results for MVPA from the present study are somewhat similar to these previous results, with Mozambican boys and girls having lower MVPA than their Portuguese peers; however, significant mean differences were observed in LPA or ST. These results can be explained in different ways. Firstly, in the last decades, Mozambique passed through a social and economic transition period, with changes in lifestyle with visible consequences in youth PA and sedentariness, especially those from urban/suburban areas ${ }^{16}$. As such, children and adolescents are more sedentary and spend less time in activities of moderate and high intensity, and this can be a possible explanation for the lower time spent in MVPA found among Mozambican youth as compared to Portuguese.

In general terms, youth from both countries do not comply, on average, with recommended MVPA levels $\left(60 \mathrm{~min} \cdot \mathrm{d}^{-1}\right)$. This low mean value reflects the percentage of children attaining the recommended MVPA guidelines: $8.3 \%$ and $7.7 \%$ in Mozambican and Portuguese boys, respectively, and only $1.3 \%$ and $1.5 \%$ in Mozambican and Portuguese girls, respectively. Although these are very low values, and of great concern, they are in accordance with the current worldwide trend which is characterized by low PA levels, in association with high ST ${ }^{10}$. For example, European youth data showed that only $4.6 \%$ of girls, and $16.8 \%$ of boys, aged 10-12 years, from 5 countries, reached the daily MVPA guidelines $^{28}$. In the African context, Muthuri, Wachira, Onywera, Tremblay ${ }^{32}$ reported that among 9-11 years old Kenyan children, only $12.6 \%$ met the MVPA recommendations, while Peltzer ${ }^{14}$ concluded that, among adolescents from eight African countries (Botswana, Kenya, Namibia, Senegal, Swaziland, Uganda, Zambia, Zimbabwe), only $14.2 \%$ spend at least $60 \mathrm{~min} \cdot \mathrm{d}^{-1}$ in MVPA on 5 or more days per week.

Results of the multiple regression analysis showed significant effects of sex, age, BMI, WTA and country on PA and sedentariness. There are consistent lines of evidence showing sex and age differences in PA, where girls and older children and adolescents tend to be less active and more sedentary ${ }^{33-35}$. Our results reinforce this trend, since girls spend less time in MVPA and LPA, as well as more time in sedentary activities; older adolescents are less engaged in LPA but are more sedentary than their younger counterparts. There is evidence that BMI is inversely associated with PA and positively associated with sedentariness ${ }^{36-38}$. Among Mozambican and Portuguese adolescents, higher BMI was associated with lower MVPA and LPA, but also with higher time spent in sedentary behaviour. This result is of concern because of the observed increases in the prevalence of overweight/obesity in young population groups during the last decades ${ }^{7,8}$. In addition, children with more WTA had more MVPA, LPA and ST as expected, since the higher the amount of time recorded by the accelerometer, the higher the time spent in different PA phenotypes and sedentary activities will be registered.

The last PA and sedentariness predictor was country of origin, and the results showed that Mozambicans tend to spend significantly less time in MVPA. It is possible that this result is related to lifestyle changes observed in Mozambique during the last decades, mostly due to the urbanization process, which lead to a decrease in leisure time activities linked with increments in electronic entertainment media use among youth as previously suggested ${ }^{39,40}$; as a result, children became less active and more sedentary ${ }^{16}$; however, because we do not have any objective information regarding this issue, we can only speculate about this possible association. In addition, there seems to exist a trend among African children and adolescents to be engaged in greater amounts of LPA as compared to MVPA ${ }^{15,32,41}$, although there were no differences in LPA observed in this study. On the other hand, a greater involvement of Portuguese children and adolescents in sports may also explain these results, since their sports practice gives them opportunities for engagement in more energy-demanding activities ${ }^{15}$.

This study is not without limitations. Firstly, it was not considered a proportional sample in each country. Furthermore, the present study did not intend to have representative samples from each city, nor from each country, as it is similar to other well-known studies ${ }^{42,43}$. Secondly, we do not have information regarding the context of the PA and sedentariness (we only focused on objectively determined overall MVPA, LPA and ST), which could provide a better understanding of the crosscountry differences. Thirdly, although cut-off points advocated by Treuth et al. ${ }^{27}$ are internationally accepted, they tend to produce lower estimates of PA than other published cut-points, which can partly explain the low percentage of children complying with the recommended 60 minutes of daily MVPA. Fourthly, we did not adjust PA or ST for biological maturation because a large number of subjects did not have information in sitting height (about $20 \%$ of the sample). Yet, as suggested by Sherar, Cumming, Eisenmann, Baxter-Jones, Malinal ${ }^{44}$, the association between biological maturity and PA is rather inconsistent.

This study also has several strengths. Firstly, the use of an objective method (accelerometer) to measure PA and ST is a marked strength. Secondly, the use of the same accelerometer 
protocol in both countries ensures a high degree of robustness in the data. Thirdly, the use of samples from very different countries in socio-economic and cultural terms provides a unique opportunity to study correlates of PA and sedentary behaviour.

\section{Conclusions}

In summary, the present study found cross-country differences in MVPA between Mozambican and Portuguese youth. In addition, in both countries, a low percentage of children complied with the recommended daily MVPA levels. In general, girls, older children and those with higher BMI tend to spend less time in MVPA and LPA and more time being sedentary. Mozambicans are less involved in MVPA than Portuguese. Since low levels of MVPA in early life are related to obesity and its comorbidities in adulthood (i.e., they track over time), promoting strategies and programs to enhance active living styles during this period should be primary public health and education targets.

\section{References}

1. Rowland TW. The biological basis of physical activity. Med Sci Sports Exerc. 1998; Mar;30(3):392-399.

2. Bouchard C, Blair SN, Haskell W. Why study physical activity and health? In: Bouchard C, Blair SN, Haskell W, editors. Physical activity and health. Champaign, Human Kinetics; 2007. p. 3-19.

3. Malina RM, Bouchard C, Bar-Or O, editors. Growth, Maturation and Physical Activiy. Champaign, Human Kinetics; 2004.

4. de Onis M, Blossner M, Borghi E, Morris R, Frongillo EA. Methodology for estimating regional and global trends of child malnutrition. Int J Epidemiol. 2004; Dec;33(6):1260-1270.

5. Vorster HH. The link between poverty and malnutrition: A South African perspective. Health SA Gesondheid. 2010;15(1):1-6.

6. Katzmarzyk PT, Mason C. The physical activity transition. J Phys Act Health. 2009; May;6(3):269-280.

7. United Nations Children's Fund WHO, The World Bank. UNICEF-WHO-World Bank,. Joint Child Malnutrition Estimates. UNICEF, New York; WHO, Geneva; The World Bank, Washington, DC2012.

8. Ng M, Fleming T, Robinson M, Thomson B, Graetz N, Margono $\mathrm{C}$, et al. Global, regional, and national prevalence of overweight and obesity in children and adults during 1980-2013: a systematic analysis for the Global Burden of Disease Study 2013. Lancet. 2014; Aug 30;384(9945):766-781.

9. Misra A, Khurana L. Obesity and the metabolic syndrome in developing countries. J Clin Endocrinol Metab. 2008; Nov;93(11 Suppl 1):S9-30.

10. Hallal PC, Andersen LB, Bull FC, Guthold R, Haskell W, Ekelund $\mathrm{U}$, et al. Global physical activity levels: surveillance progress, pitfalls, and prospects. Lancet. 2012; Jul 21;380(9838):247-257.

11. Muthuri SK, Wachira LJ, Leblanc AG, Francis CE, Sampson M, Onywera VO, et al. Temporal trends and correlates of physical activity, sedentary behaviour, and physical fitness among schoolaged children in Sub-Saharan Africa: a systematic review. Int J Environ Res Public Health. 2014; Mar;11(3):3327-3359.
12. Aibar A, Bois JE, Generelo E, Zaragoza Casterad J, Paillard T. A cross-cultural study of adolescents' physical activity levels in France and Spain. Eur J Sport Sci. 2013;13(5):551-558.

13. Ramirez-Rico E, Hilland TA, Foweather L, Fernandez-Garcia E, Fairclough SJ. Weekday and weekend patterns of physical activity and sedentary time among Liverpool and Madrid youth. Eur J Sport Sci. 2014;14(3):287-293.

14. Peltzer K. Leisure time physical activity and sedentary behavior and substance use among in-school adolescents in eight African countries. Int J Behav Med. 2010; Dec;17(4):271-278.

15. Prista A, Nhantumbo L, Silvio S, Lopes V, Maia J, Andre e S, et al. Physical activity assessed by accelerometry in rural African school-age children and adolescents. Pediatr Exerc Sci. 2009; Nov;21(4):384-399.

16. dos Santos FK, Maia JA, Gomes TN, Daca T, Madeira A, Damasceno A, et al. Secular trends in habitual physical activities of Mozambican children and adolescents from Maputo city. Int J Environ Res Public Health. 2014;11(10):10940-10950.

17. Baptista F, Santos DA, Silva AM, Mota J, Santos R, Vale S, et al. Prevalence of the Portuguese population attaining sufficient physical activity. Med Sci Sports Exerc. 2012; Mar;44(3):466-473.

18. Prista A, Maia J, Nhantumbo L, Saranga S, Jani I, Damasceno A, et al. Do problema, do desenho e dos métodos. Variabilidade biológica humana em Moçambique: a visão, as pessoas e a estrutura de um projecto nacional de impacto internacional. In: Prista A, Maia J, Nhantumbo L, Saranga S, editors. O desafio de Calanga - Do lugar e das pessoas à aventura da ciência. Porto, Faculdade de Desporto da Universidade do Porto; 2010. p. 29-46.

19. de Souza MC, de Chaves RN, dos Santos FK, Gomes TNQF, Santos DVE, Borges AS, et al. The Oporto mixed-longitudinal growth, health and performance study. Design, methods and baseline results. Annals of human biology. 2017; Feb;44(1):11-20.

20. INE. Instituto Nacional de Estatística de Moçambique Indicadores. 2014 [cited 2014 6th August]; Available from: http:// www.ine.gov.mz/pt/DataAnalysis.

21. Concelho Municipal de Maputo. Perfil Estatístico do Município de Maputo. Maputo, Concelho Municipal de Maputo; 2013.

22. Fundação Francisco Manuel dos Santos. PORDATA. 2014 [cited 2014 6th August]; Available from: http://www.pordata.pt.

23. Associação Industrial Portuguesa. Cartas Regionais de Competitividade | Minho-Lima | Ave-Cávado | Tâmega | Grande Porto | Entre Douro e Vouga. Lisboa, AIP; 2011.

24. Lohman T, Roche A, Martorell E, editors. Anthropometric standardization reference manual. Champaign, Human Kinetics; 1988.

25. Cole TJ, Bellizzi MC, Flegal KM, Dietz WH. Establishing a standard definition for child overweight and obesity worldwide: international survey. BMJ. 2000; May 6;320(7244):1240-1243.

26. Barreira TV, Schuna Jr JM, Mire EF, Katzmarzyk PT, Chaput J-P, Leduc G, et al. Identifying children's nocturnal sleep using 24-hour waist accelerometry. Med Sci Sports Exerc. In press.

27. Treuth MS, Schmitz K, Catellier DJ, McMurray RG, Murray DM, Almeida MJ, et al. Defining accelerometer thresholds for activity intensities in adolescent girls. Med Sci Sports Exerc. 2004; Jul;36(7):1259-1266.

28. Verloigne M, Van Lippevelde W, Maes L, Yildirim M, Chinapaw M, Manios Y, et al. Levels of physical activity and sedentary 
time among 10- to 12-year-old boys and girls across 5 European countries using accelerometers: an observational study within the ENERGY-project. Int J Behav Nutr Phys Act. 2012;9:34.

29. Ferreira I, van der Horst K, Wendel-Vos W, Kremers S, van Lenthe FJ, Brug J. Environmental correlates of physical activity in youth - a review and update. Obesity Reviews. 2007; Mar;8(2):129-154.

30. Pan SY, Cameron C, DesMeules M, Morrison H, Craig CL, Jiang $\mathrm{X}$. Individual, social, environmental, and physical environmental correlates with physical activity among Canadians: a crosssectional study. BMC Public Health. 2009;9(21).

31. Ekelund U, Tomkinson G, Armstrong N. What proportion of youth are physically active? Measurement issues, levels and recent time trends. Br J Sports Med. 2011; Sep;45(11):859-865.

32. Muthuri SK, Wachira LJ, Onywera VO, Tremblay MS. Correlates of objectively measured overweight/obesity and physical activity in Kenyan school children: results from ISCOLE-Kenya. BMC Public Health. 2014;14:436.

33. Sallis JF, Prochaska JJ, Taylor WC. A review of correlates of physical activity of children and adolescents. Med Sci Sports Exerc. 2000; May;32(5):963-975.

34. Van Der Horst K, Paw MJ, Twisk JW, Van Mechelen W. A brief review on correlates of physical activity and sedentariness in youth. Med Sci Sports Exerc. 2007; Aug;39(8):1241-1250.

35. Pate RR, Mitchell JA, Byun W, Dowda M. Sedentary behaviour in youth. Br J Sports Med. 2011; Sep;45(11):906-913.

36. Decelis A, Jago R, Fox KR. Physical activity, screen time and obesity status in a nationally representative sample of Maltese youth with international comparisons. BMC Public Health. 2014; 14:664.

37. Janssen I, Katzmarzyk PT, Boyce WF, King MA, Pickett W. Overweight and obesity in Canadian adolescents and their associations with dietary habits and physical activity patterns. J Adolesc Health. 2004; Nov;35(5):360-367.

38. King AC, Parkinson KN, Adamson AJ, Murray L, Besson H, Reilly JJ, et al. Correlates of objectively measured physical activity and sedentary behaviour in English children. Eur J Public Health. 2011; Aug;21(4):424-431.

39. Prista A, Magaia S, Silva-Matos C, Damasceno A. Saúde, estilo de vida e urbanização em Moçambique: Problemas e perspectivas. Rev Moçambicanada de Ciên de Saúde. 2014;1(1):11-21.

40. Prista A, Santos F, Mangona L, Nhantumbo L. Pesquisa em Moçambique no domínio da actividade física: uma revisão do estado da arte. Rev Cient UEM: Sér Ciênc Bioméd Saúde Pública. 2016;1(3):54-71.
41. Craig E, Bland R, Reilly J. Objectively measured physical activity levels of children and adolescents in rural South Africa: high volume of physical activity at low intensity. Appl Physiol Nutr Metab. 2013; Jan;38(1):81-84.

42. Riddoch C, Edwards D, Page A, Froberg K, Anderssen S, Wedderkopp N, et al. The European Youth Heart Study cardiovascular disease risk factors in children: rationale, aims, study design and validation of methods. J Phys Act Health. 2005;2:115-129.

43. Katzmarzyk PT, Barreira TV, Broyles ST, Champagne CM, Chaput JP, Fogelholm M, et al. The International Study of Childhood Obesity, Lifestyle and the Environment (ISCOLE): design and methods. BMC Public Health. 2013;13:900.

44. Sherar LB, Cumming SP, Eisenmann JC, Baxter-Jones AD, Malina RM. Adolescent biological maturity and physical activity: biology meets behavior. Pediatr Exerc Sci. 2010; Aug;22(3):332-349.

\section{Acknowledgments}

We would like to thank the NIAFS research team, Faculty of Physical Education and Sports (Pedagogical University of Maputo) for data collection in Mozambique, and the Kinanthropometry Laboratory research team, Faculty of Sport (University of Porto), for data collection in Portugal.

\section{Corresponding author}

Fernanda Karina dos Santos

Universidade Federal de Viçosa, Departamento de Educação Física.

Avenida Peter Henry Rolfs, s/nº Campus Universitário, 36570-900, Viçosa,MG.

Email: fernandak.santos@ufv.br

Manuscript received on June 29, 2017

Manuscript accepted on Augsut 31, 2017

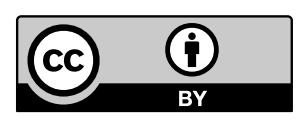

Motriz. The Journal of Physical Education. UNESP. Rio Claro, SP, Brazil - eISSN: 1980-6574 - under a license Creative Commons - Version 3.0 